\title{
Avaliação da transferência de citocinas para bezerros neonatos via ingestão de colostro de fêmeas bovinas Holandesas ${ }^{1}$
}

\author{
Carolina L. Shecaira ${ }^{2 *}$, Karina M. Madureira ${ }^{3}$, Viviani Gomes ${ }^{2}$, Caroline H. Seino ${ }^{2}$, Rogerio \\ B. dos Santos ${ }^{2}$, Juliana A. Bombardelli ${ }^{2}$, Gabriela A. Reis ${ }^{2}$ e Fernando J. Benesi ${ }^{2}$
}

\begin{abstract}
Shecaira C.L., Madureira K.M., Gomes V., Seino C.H., Santos R.B., Bombardelli J.A., Reis G.A. \& Benesi F.J. 2014. [Evaluation of the transfer of cytokines to the blood of neonates by colostrum ingestion of Holstein females.] Avaliação da transferência de citocinas para o sangue de bezerros neonatos via ingestão de colostro de fêmeas bovinas Holandesas. Pesquisa Veterinária Brasileira 34(12):1271-1275. Departamento de Clínica Veterinária, Faculdade de Medicina Veterinária e Zootecnia, Universidade de São Paulo, Av. Orlando Marques Paiva 87, São Paulo, SP 05508-270, Brazil. E-mail: carolina.shecaira@gmail.com

To evaluate the transfer of cytokines into the blood of neonates via colostrum intake of Holstein cows were used 15 calves born from eutocic, shared equally by three experimental groups ( $\mathrm{n}=5$ ) G1-received 2 liters of fresh colostrum from their own mothers, G2-received 2 liters of colostrum from the "pool" of frozen colostrum and G3-were fed only milk. These group blood samples were collected at five times during the first fifteen days and measured the concentrations of IL-1 $\beta$, IL-6, TNF- $\alpha$ and IFN- $\gamma$. Also measured are the cytokines IL- $1 \beta$, IL- 6 and TNF- $\alpha$ in the supernatant of colostrum fed to calves from G1, and cytokines IL-1 $\beta$ , IL-6 , TNF- $\alpha$ and IFN- $\gamma$ in the supernatant the "pool " of colostrum fed to calves in G2 . It is the transfer of IL - $1 \beta$, IL- 6 , TNF- $\alpha$ and IFN- $\gamma$ in the serum of calves from G1 whereas the other groups G2 and G3 were not detected.
\end{abstract}

INDEX TERMS: Newborn calves, transfer of passive immunity, cytokines, Holstein cows.

RESUMO.- Para a avaliação da transferência de citocinas para o sangue de bezerros neonatos via ingestão de colostro de fêmeas bovinas holandesas, foram utilizados 15 bezerros nascidos de parto eutócico, distribuídos igualmente por três grupos experimentais ( $\mathrm{n}=5)$ : G1- receberam dois litros de colostro fresco provenientes de suas próprias mães; G2- receberam dois litros de colostro provenientes de "pool" de colostro congelado e o G3- foram alimentados apenas com leite. Nestes grupos foram coletadas amostras de sangue em cinco tempos durante os primeiros quinze dias de vida e mensuradas as concentrações das citocinas Interleucina-1 $\beta$ (IL-1 $\beta$ ), Interleucina-6 (IL-6), Fator de necrose tumoral- $\alpha$ (TNF- $\alpha$ ) e Interferon- $\gamma$ (IFN- $\gamma$ ). Também se mensurou tais citocinas (IL-1 $\beta$, IL-6 e TNF- $\alpha$ ) nos sobrena-

\footnotetext{
${ }^{1}$ Recebido em 1 de abril de 2014.

Aceito para publicação em 5 de novembro de 2014.

2 Departamento de Clínica Veterinária, Faculdade de Medicina Veterinária e Zootecnia, Universidade de São Paulo (USP), Av. Orlando Marques Paiva 87, São Paulo, SP 05508270, Brasil. *Autor para correspondência: carolina.shecaira@gmail.com

${ }^{3}$ Departamento de Anatomia, Patologia e Clínicas Veterinárias, Escola de Medicina Veterinária e Zootecnia, Universidade Federal da Bahia (UFBA), Av. Adhemar de Barros 500, Salvador, BA 40170-110, Brasil.
}

dantes do colostro de do "pool" de colostro fornecidos aos bezerros dos grupos G1 e G2 respectivamente. Verificou-se a transferência das citocinas IL-1 $\beta$, IL- 6 , TNF- $\alpha$ e IFN- $\gamma$ pela presença no soro dos bezerros do grupo G1, enquanto que nos demais grupos (G2 e G3) não foram detectadas.

TERMOS DE INDEXAÇÃO: Bezerros neonatos, transferência de imunidade passiva, citocinas, gado Holandês.

\section{INTRODUÇÃO}

O desenvolvimento adequado do sistema imune de um bovino recém-nascido determina sua sobrevivência e sua capacidade de responder a microrganismos presentes no ambiente, dando-se mais rapidamente com o fornecimento do colostro ao bezerro (Morein et al. 2002, Chase et al. 2008, Tizard 2008, Cortese 2009), pois este atua como um suporte imunológico muito importante, por propiciar a transferência de imunidade passiva. Além de conter nutrientes para suprir as demandas energéticas imediatas do recém-nascido, também se compõe de fatores imunitários, que lhes confere a imunidade passiva, destacando-se as imunoglobulinas cujas funções estão bem esclarecidas quanto à participação nessa imunidade passiva (Benesi 
1993, Moraes et al. 1997, Feitosa et al. 2001, 2010, Soares Filho et al. 2001, Hill 2010). Ademais, não são somente as imunoglobulinas, que representam esses fatores imunitários do colostro, mas também leucócitos (Riedel-Caspari 1993, Reber et.al. 2006, Chase et al. 2008, Gomes 2008) e citocinas (Sordillo et al. 1991, Goto et.al. 1997, Hagiwara et al. 2001, Yamanaka et.al. 2003a, 2003b, Madureira 2011).

Quanto aos leucócitos colostrais, é reconhecido que contribuem para o rápido desenvolvimento das células apresentadoras de antígenos nos bezerros, que serão a chave para as respostas da imunidade adquirida frente a patógenos e vacinações (Chase et al. 2008), amplificando a resposta linfocitária neonatal, conferindo-lhes efeitos bactericidas no intestino, além de produzirem as citocinas (Barrington \& Parish 2001).

As citocinas também têm seu papel no desenvolvimento do sistema imune do recém-nascido, estudado em várias espécies animais, mas ainda não esclarecido totalmente. Estudos evidenciaram que as citocinas ingeridas pelos bezerros via colostro produzem a ativação de células imunes, arregimentando e ativando neutrófilos e linfócitos do sangue periférico dos recém-nascidos (Yamanaka et al. 2003b).

Em linhas gerais os componentes imunitários do colostro bovino têm sido estudados, particularmente os teores e a função das imunoglobulinas, seguidos por pesquisas sobre os leucócitos e suas ações, porém, quanto às citocinas e sua transferência aos neonatos via colostro, poucos são os artigos existentes. Também não é do conhecimento dos autores, existência de pesquisas que avaliaram a influência do manejo do colostro na transferência de citocinas para os bezerros neonatos, motivo pelo qual neste trabalho objetivou-se avaliar os perfis dos teores séricos de algumas citocinas (IL-1, IL-6, TNF- $\alpha$, IFN- $\gamma$ ), em de bezerros alimentados com colostro fresco e "pool" de colostro congelado nos primeiros 15 dias pós-nascimento (p.n.).

\section{MATERIAL E MÉTODOS}

Este trabalho está de acordo com os princípios éticos de experimentação animal da "Comissão de Ética no uso de animais" da Faculdade de Medicina Veterinária e Zootecnia da Universidade de São Paulo, sob protocolo de $\mathrm{n}^{\circ} 2194 / 2011$, Aprovado em 04/05/2011.

Para a avaliação das citocinas IL-1 $\beta$, IL-6, TNF- $\alpha$ e IFN- $\gamma$ no soro dos bezerros foram utilizados 15 neonatos holandeses nascidos de parto eutócico, separados de suas mães imediatamente após o nascimento e distribuídos igualmente por três grupos $(G)$ experimentais $(n=5)$ : $G 1$-que recebeu dois litros de colostro fresco provenientes de suas mães; G2- que recebeu dois litros de colostro originados de "pool" de colostro congelado e o G3- alimentado apenas com leite em pó reconstituído. A seguir os animais dos três grupos foram alimentados com leite em volume complementar ao equivalente a $10 \%$ do seu peso vivo, em suas primeiras 24 horas p.n. e durante os 15 dias de experimentação além do leite, foi disponibilizado "ad libitum" água e ração inicial para bezerros.

Os tempos determinados para as colheitas das amostras de sangue foram: Tempo 0 (T0)-realizada no primeiro dia de vida (antes da ingestão do colostro); Tempo 1 (T1): efetuada com 1 a 2 dias p.n.; Tempo 2 (T2)- realizada com 3 a 4 dias p.n.; Tempo 3 (T3)- realizada com 5 a 6 dias p.n. e Tempo 4 (T4)- efetuada com 10 a 15 dias p.n. As amostras de sangue foram obtidas por meio de punção da veia jugular, utilizando-se tubo siliconizado, sem an- ticoagulante e agulha para múltiplas colheitas $(25 \mathrm{~mm} \times 8 \mathrm{~mm})$ do sistema Vacutainer ${ }^{\circledR}$.

As amostras de soro foram obtidas após sinérese do sangue e centrifugação a $730 \mathrm{G}$ por 20 minutos em centrífuga comum, sendo armazenadas em freezer a $-80^{\circ} \mathrm{C}$. Amostras de colostro fresco, fornecido aos animais do grupo G1 e do "pool" de colostro fornecido ao grupo G2, foram centrifugadas para a obtenção do sobrenadante em centrífuga refrigerada a $4^{\circ} \mathrm{C}$, com velocidade de $6.000 \mathrm{G}$, durante 30 minutos. A camada de gordura foi desprezada, aspirando-se apenas o sobrenadante dos colostros e acondicionando-os em frascos com capacidade para $1 \mathrm{~mL}$, mantidos em freezer $-80^{\circ} \mathrm{C}$ até $\mathrm{o}$ momento da dosagem das citocinas.

Para a mensuração das citocinas IL-1 $\beta$, IL-6, TNF- $\alpha$ e IFN- $\gamma$ utilizou-se kits comerciais para teste de ELISA da marca BD $^{\circledR}$, destinado ao uso humano, porém com homologia entre as citocinas de espécies diferentes suficientes para haver reação cruzada, como recomendado por Scheerlinck (1999) sendo os resultados expressos em pg/mL. Para a análise estatística descritiva dos dados foram calculados a média, mediana, valores máximo, mínimo e desvios padrão. As medianas foram submetidas ao teste não paramétrico de Kruskal Wallis e comparação múltipla com o teste de Bonferroni.

\section{RESULTADOS}

Os bezerros do grupo G1 que receberam colostro fresco de suas mães apresentaram concentrações detectáveis pelo método de ELISA para as citocinas IL-1 $\beta$, IL6, TNF- $\alpha$ e IFN- $\gamma$. 0 grupo de bezerros G2, que recebeu "pool" de colostros congelados apresentou teores mensuráveis apenas para a citocina IL-6 e o grupo G3 não apresentou taxas detectáveis para qualquer das citocinas mensuradas (Fig.1, Quadro 1).

Quadro 1. Valores medianos das taxas de citocinas

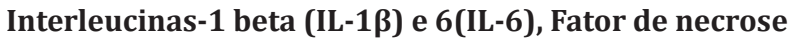
tumoral-alfa (TNF- $\alpha$ ) e Interferon-gama (IFN- $\gamma$ ), dos grupos de bezerros G1 (colostro fresco materno), G2 ("pool" de colostro congelado) e G3 (apenas leite), nos tempos T0 (antes da mamada do colostro), T1 (1-2 dias p.n.), T2 (3-4 dias p.n.), T3 (5-6 dias p.n.) e T4 (10-15 dias p.n.)

\begin{tabular}{lccccc}
\hline Citocina & \multicolumn{5}{c}{ IL- $1 \beta$} \\
\cline { 2 - 6 } Mediana/tempo & T0 & T1 & T2 & T3 & T4 \\
\cline { 2 - 6 } Grupo G1 & $1,265^{\mathrm{a}}$ & $9,445^{\mathrm{a}}$ & $11,56^{\mathrm{a}}$ & $1,89^{\mathrm{a}}$ & $3,4^{\mathrm{a}}$ \\
Grupo G2 & $0^{\mathrm{b}}$ & $0^{\mathrm{b}}$ & $0,01432^{\mathrm{a}}$ & $0^{\mathrm{a}}$ & $0^{\mathrm{a}}$ \\
Citocina & $0^{\mathrm{b}}$ & $0^{\mathrm{b}}$ & $0^{\mathrm{b}}$ & $0^{\mathrm{a}}$ & $0,0793^{\mathrm{a}}$ \\
Mediana/tempo & & & $\mathrm{IL}-6$ & & \\
Grupo G1 & $\mathrm{T} 0$ & $\mathrm{~T} 1$ & $\mathrm{~T} 2$ & $\mathrm{~T} 3$ & $\mathrm{~T} 4$ \\
Grupo G2 & $0,25^{\mathrm{a}}$ & $0,86^{\mathrm{a}}$ & $3,88^{\mathrm{a}}$ & $2,12^{\mathrm{a}}$ & $1,245^{\mathrm{a}}$ \\
Grupo G3 & $0^{\mathrm{a}}$ & $0^{\mathrm{a}}$ & $0^{\mathrm{a}}$ & $1,194^{\mathrm{b}}$ & $0^{\mathrm{b}}$ \\
Citocina & $0^{\mathrm{a}}$ & $0^{\mathrm{a}}$ & $0^{\mathrm{a}}$ & $0^{\mathrm{c}}$ & $0^{\mathrm{b}}$ \\
Grupo/tempo & & & $\mathrm{TNF}-\alpha$ & & \\
G1 & $\mathrm{T} 0$ & $\mathrm{~T} 1$ & $\mathrm{~T} 2$ & $\mathrm{~T} 3$ & $\mathrm{~T} 4$ \\
G2 & $0^{\mathrm{a}}$ & $2,37^{\mathrm{a}}$ & $0,99^{\mathrm{a}}$ & $0^{\mathrm{a}}$ & $0^{\mathrm{a}}$ \\
G3 & $0^{\mathrm{a}}$ & $0^{\mathrm{b}}$ & $0^{\mathrm{b}}$ & $0^{\mathrm{a}}$ & $0^{\mathrm{a}}$ \\
Citocina & $0^{\mathrm{a}}$ & $0^{\mathrm{b}}$ & $0^{\mathrm{b}}$ & $0^{\mathrm{a}}$ & $0^{\mathrm{a}}$ \\
Grupo/tempo & & & $\mathrm{IFN}-\gamma$ & & \\
G1 & $\mathrm{T} 0$ & $\mathrm{~T} 1$ & $\mathrm{~T} 2$ & $\mathrm{~T} 3$ & $\mathrm{~T} 4$ \\
G2 & $\mathrm{ND}^{\mathrm{a}}$ & $0^{\mathrm{a}}$ & $4,401^{\mathrm{a}}$ & $10,18^{\mathrm{a}}$ & $0^{\mathrm{a}}$ \\
G3 & $\mathrm{ND}^{\mathrm{a}}$ & $0^{\mathrm{a}}$ & $0^{\mathrm{b}}$ & $0^{\mathrm{b}}$ & $0^{\mathrm{a}}$ \\
\hline
\end{tabular}

$\overline{\mathrm{a}, \mathrm{b}, \mathrm{c}}$ Valores medianos com letras minúsculas diferentes na mesma linha indicam diferenças estatísticas entre si.

ND = Não dosado. 

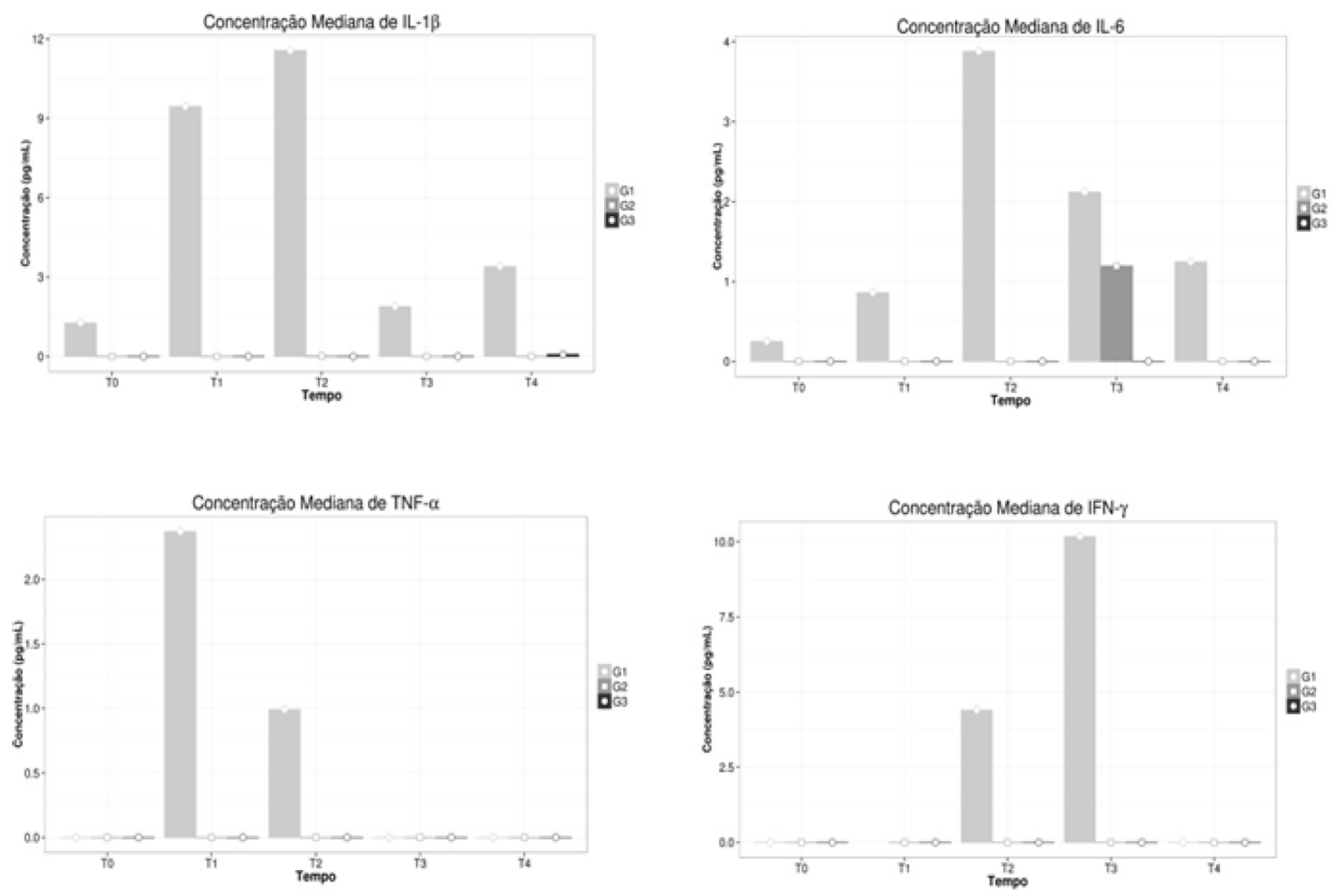

Fig.1. As variações das taxas das citocinas Interleucinas-1 beta (IL-1 $\beta$ ) e 6 (IL-6), Fator de necrose tumoral-alfa (TNF- $\alpha$ ) e Interferon-gama (IFN- $\gamma$ ), no sangue de bezerros dos grupos G1(colostro materno fresco), G2 ("pool" de colostro congelado) e G3 (apenas leite), nos tempos T0 (antes da mamada de colostro), T1(1-2 dias p.n.), T2 (3-4 dias p.n.), T3 (5-6 dias p.n.) e T4 (10-15 dias p.n.).

\section{DISCUSSÃO}

As concentrações das citocinas IL-1 $1 \beta$, IL-6, TNF- $\alpha$ e IFN- $\gamma$, foram mensuradas no soro dos bezerros dos grupos G1, G2 e G3, nos tempos T0, T1, T2, T3 e T4 que abrangeram os primeiros quinze dias de vida p.n. desses neonatos, (com exceção do tempo T1 do grupo G1 para IFN- $\gamma$ ). Destaca-se inicialmente os raros trabalhos com estudo das concentrações dessas citocinas no soro de bezerros recém-nascidos, o que limitou a comparação dos dados obtidos no presente trabalho com aqueles da literatura disponível (Goto et al. 1997, Yamanaka et al. 2003b, Madureira 2011). Além do que, não foram encontrados trabalhos realizados especializados em bezerros recém-nascidos que tenham estudado a interferência do manejo do colostro ou não fornecimento deste na transferência de citocinas.

Goto et al. (1997), ao mensurarem a interleucina $1 \beta$ no soro de bezerros recém-nascidos, puderam observar taxas máximas dessa citocina no terceiro dia após o nascimento e recebimento de colostro $(1.000 \mathrm{pg} / \mathrm{mL})$. Após este momento, houve um decréscimo, passando a estar ausente aos 14 dias.

Yamanaka et al. (2003b) mensuraram as mesmas citocinas (IL-1 $\beta$, IL-6, TNF- $\alpha$ e IFN- $\gamma$ ), além do receptor agonista da IL-1, no momento do nascimento, às 12 horas após o nascimento, com um dia p.n., três dias p.n., cinco dias p.n. sete dias p.n. 14 dias p.n., 21 dias p.n. e 28 dias p.n. Os valores máximos encontrados por esses autores para as citocinas IL-1 $\beta$, IL-6, TNF- $\alpha$ e IFN- $\gamma$ foram respectivamente, de $1.023 \mathrm{pg} / \mathrm{mL} ; 46.900 \mathrm{pg} / \mathrm{mL} ; 190 \mathrm{pg} / \mathrm{mL}$ e $690 \mathrm{pg} / \mathrm{mL}$, verificados no tempo de 24 horas pós-ingestão do colostro, havendo clara relação da constatação com a ingestão de colostro.
Madureira (2011) mensurou a concentração sérica de três dessas citocinas (IL-1 $\beta$, IL- 6 e TNF- $\alpha$ ), em bezerros recém-nascidos que receberam colostro de suas mães em quatro momentos pós-nascimento. Estas citocinas não apresentaram valores detectáveis no tempo zero (antes do fornecimento de colostro) e nos tempos seguintes de 24, 72,96 horas p.n. as concentrações de citocinas foram mensuráveis, alcançando seus valores medianos máximos em 72 horas após a ingestão do colostro: 4,29pg/mL (IL-1 $\beta$ ), $3,80 \mathrm{pg} / \mathrm{mL}$ (IL-6) e 6,20pg/mL (TNF- $\alpha$ ). Aos 15 dias pós-nascimento não foram mais detectadas.

Nesta pesquisa, os bezerros alimentados com colostro fresco materno (grupo G1) apresentaram respectivamente os seguintes valores medianos máximos para as citocinas IL-1 $\beta$, IL-6, TNF- $\alpha$ e IFN- $\gamma: 11,56 ; 3,88 ; 2,37$ e $10,18 \mathrm{pg} / \mathrm{mL}$. 0 contraste e diferença de taxas obtidas pode ser decorrência da diversidade entre os kits de ELISA empregados, e que neste trabalho, como já citado anteriormente era um kit de uso humano. De fato, Madureira (2011), valendo-se do mesmo kit de ELISA obteve os resultados anteriormente descritos, com concentrações medianas das citocinas avaliadas próximas das obtidas nesta pesquisa. Por outro lado, Goto et al. (1997) ao utilizarem um kit de ELISA próprio para a espécie bovina, com maior sensibilidade para essa espécie animal, obtiveram concentrações com maior magnitude do que as encontradas neste trabalho.

A interleucina IL-1 $\beta$ apresentou valores medianos de $1,265 \mathrm{pg} / \mathrm{mL}$ no tempo T0, correspondente ao primeiro momento p.n. e antes da ingestão de colostro. No trabalho conduzido por Goto et al.(1997) também constataram pequenas concentrações de IL-1 $\beta$, antes da mamada do colostro. Apesar da condição hipo ou agamaglobulinêmica dos 
bezerros em decorrência da impermeabilidade da placenta a macromoléculas, esta baixa concentração de citocina IL-1 $\beta$ sugere que pode ter havido passagem de pequenas concentrações das citocinas por essa via (Goto et al. 1997).

As interleucinas- $1 \beta$ e 6 tiveram suas maiores taxas demonstradas no tempo T2 (3 a 4 dias p.n.), 11,56pg/mL e $3,88 \mathrm{pg} / \mathrm{mL}$ respectivamente, resultados esses que se assemelharam àqueles encontrados por Goto et al. (1997) para a citocina IL-1 $\beta$ e por Madureira (2011), para estas mesmas citocinas. A citocina TNF- $\alpha$ teve sua maior concentração no tempo T1 (1 a 2 dias) 2,37pg/mL, resultado semelhante ao encontrado por Yamanaka et. al. (2003b). Diferentemente das demais citocinas avaliadas, o IFN- $\gamma$, apresentou seu valor máximo mais tardiamente, ou seja, aos 5 a 6 dias $(10,18 \mathrm{pg} / \mathrm{mL})$, correspondente ao momento T3, tendo este resultado discordância daqueles encontrados na literatura (Yamanaka et al. 2003b, Madureira 2011). Entende-se que parte da concentração da citocina IFN- $\gamma$ encontrada no soro de bezerros aos 5 a 6 dias de vida, incluiria além daquela parcela absorvida pela ingestão de colostro, uma outra que teria sido produzida por células colostrais absorvidas pelo trato intestinal, considerando-se que estas células ficam circulantes durante três a cinco semanas no organismo do bezerro (Cortese 2009).

Zaitseva et al. (1995) demonstraram que populações de linfócitos T CD4+ e CD8+ humanos, desafiados com Brucella abortus inativados, produziram grandes quantidades de citocina IFN- $\gamma$, no período compreendido entre os cinco a sete dias após o desafio realizado in vitro. Este resultado, encontrado por Zaitseva et al. (1995), corrobora com a hipótese de que o Interferon- $\gamma$ tenha sido produzido por linfócitos provenientes do colostro absorvidos via intestinal, tendo em vista que os outros grupos avaliados nos quais essas células não estavam presentes não expressaram valores detectáveis dessa citocina.

Animais que compuseram o grupo G2 não tiveram valores medianos detectáveis para as citocinas mensuradas com exceção do tempo T3 (5 a 6 dias) para a concentração de IL-6 (1,194pg/mL). Apesar de, todas as citocinas possuírem concentrações detectáveis na amostra do sobrenadante "pool" de colostro fornecido aos animais desse grupo, não foi possível a demonstração dessa transferência, pós-ingestão do "pool" de colostro pelos bezerros nos momentos avaliados, para as citocinas IL- $1 \beta$, IFN- $\gamma$ e TNF- $\alpha$. Deve-se destacar que esse fato ocorreu apesar de que quando comparadas as medianas dos teores das citocinas IL-1 $\beta$, IL-6, TNF- $\alpha$ e IFN- $\gamma$, presentes nos sobrenadantes do colostro fornecido aos bezerros do grupo G1, com aquelas mensuradas no sobrenadante do "pool" de colostro fornecido aos bezerros do grupo G2, não terem sido observadas diferenças estatísticas entre elas. Considerando-se o manejo do "pool" de colostro, talvez possamos buscar fatores que elucidem este comportamento.

0 "pool" de colostro foi congelado em freezer $-20^{\circ} \mathrm{C}$, após a mistura de todos os colostros que o compuseram. Quando consultada a literatura para averiguar as possíveis alterações do colostro decorrente do congelamento, pode-se verificar diferentes respostas para as citocinas e células do colostro frente a esse tipo de conservação. Estudos re- alizados por Ramírez-Santana et al. (2012) demonstraram que citocinas colostrais humanas permaneceram com a mesma concentração inicial mesmo após terem sido mantidas sob congelamento a $-20^{\circ} \mathrm{C} \mathrm{e}-80^{\circ} \mathrm{C}$ por seis meses. No entanto, as células colostrais sofreram lise e, portanto inviabilização funcional após o processo de congelamento e descongelamento (Aldridge et al. 1998, Gomes 2008).

Gomes (2008), encontrou 878.466 células/mL no colostro de primeira ordenha de fêmeas bovinas holandesas, sendo estas representadas em sua maioria por macrófagos e células epiteliais, seguidas numericamente por linfócitos e neutrófilos. É reconhecido que os macrófagos possuem alta capacidade de produção das citocinas IL-1 $\beta$, Il-6, TNF- $\alpha$ e IFN- $\gamma$ (Tizard 2008, Bannerman 2009), demonstrando-se indiretamente que os leucócitos presentes no colostro fresco, absorvidos via epitélio intestinal (placas de Peyer) (Liebler-Tenório et al. 2002) são capazes de produzir citocinas (Barrington \& Parish 2001) no período que se encontram circulantes no sangue dos bezerros, ou seja cerca de três a cinco semanas pós-ingestão do colostro (Cortese 2009).

0 aquecimento do "pool" de colostro em banho-maria a $37^{\circ} \mathrm{C}$ para o fornecimento aos bezerros do grupo G2 pode ter interferido na concentração final das citocinas avaliadas. Ressalta-se que a mensuração das citocinas no "pool" de colostro foi realizada utilizando-se uma alíquota retirada logo após a mistura dos colostros, sendo posteriormente congelada a $-80^{\circ} \mathrm{C}$ até o momento da realização do teste de ELISA, destacando-se que não foram aliquotadas amostras deste "pool" de colostro após o aquecimento em banho-maria a $37^{\circ} \mathrm{C}$ o que não permite a comprovação da hipótese de um efeito decorrente do aquecimento. Não foram encontrados trabalhos descrevendo a possível influencia desse tipo de tratamento em colostro bovino, entretanto, Ewaschuk et al. (2011) analisaram o comportamento das taxas de citocinas IL-1 $\beta$, IFN- $\gamma$ e TNF- $\alpha$ após congelamento, aquecimento e pasteurização de um "pool" de leite humano. Verificaram que após a pasteurização a $62,5^{\circ} \mathrm{C}$ durante 30 minutos ocorreu decréscimo acentuado na concentração dessas citocinas. A elucidação da diferença entre as transferências de citocinas via colostro fresco materno e "pool" de colostro para os bezerros do grupo G1 e G2, respectivamente, parece estar vinculada ao manejo que o "pool" de colostro recebeu, resultando em diminuição da qualidade imunológica dos colostros que o compunham, seja pela lise das células leucocitárias, seja pela possível perda de citocinas. Ressalte-se a necessidade de que frente aos conhecimentos atuais dos componentes imunológicos do colostro mais trabalhos sejam realizados determinando a concentração de citocinas no colostro após o congelamento e aquecimento em banho-maria, pois são práticas corriqueiras usadas no manejo e conservação do colostro. Em relação a possíveis recomendações sobre a colostragem em fazendas leiteiras, deve-se privilegiar o fornecimento do colostro fresco materno aos bezerros recém-nascidos, na impossibilidade de tal manejo, observar rigorosamente para que o aquecimento do colostro não ultrapasse a temperatura de $37^{\circ} \mathrm{C}$, para evitar a suposta volatilização ou destruição das citocinas.

0 grupo G3, que não recebeu colostro, mamando apenas leite em pó reconstituído durante os quinze dias p.n., não 
apresentou concentrações detectáveis das citocinas avaliadas em nenhum dos momentos mensurados, corroborando com a hipótese de que essas citocinas pró-inflamatórias encontradas nos primeiros 15 dias de vida dos bezerros são provenientes do colostro.

Pode-se concluir que as citocinas IL-1 $\beta$, Il- 6 , TNF- $\alpha$ e IFN- $\gamma$ mensuradas no sangue de bezerros até 15 dias de vida são provenientes do colostro ingerido, uma vez que os bezerros do grupo que não mamou colostro, não apresentaram concentrações medianas detectáveis para as mesmas. Quanto às diferenças na concentração das citocinas no sangue dos bezerros alimentados com colostro fresco (G1) ou com "pool" de colostro (G2), a concentração maior das referidas citocinas nos tempos mensurados presente no grupo G1 em relação àquelas do grupo G2 está provavelmente relacionada com a presença de células no colostro fresco, e a sua capacidade de produzir citocinas (Barrington \& Parish 2001), fato que não ocorreu no "pool" de colostro submetido ao congelamento e aquecimento em banho-maria (Aldridge et al. 1998, Gomes 2008).

Agradecimentos.- À FAPESP pelas concessões da bolsa de mestrado (Proc. 2011/1620-8) e de Auxílio Pesquisa (Proc.2009/10394-0) e à Cláudia Regina Stricagnolo Técnica do laboratório de Imunodiagnóstico do Departamento de Clínica Médica da FMVZ/USP pelo auxílio prestado na etapa realizada em laboratório.

\section{REFERÊNCIAS}

Aldridge B.M., McGuirk S.M. \& Lunn D.P. 1998. Effect of colostral ingestion on immunoglobulin-positive cells in calves. Vet. Immunol. Immunopathol. 62:51-64.

Bannerman D.D. 2009. Pathogen-dependent induction of cytokines and other soluble inflammatory mediators during intramammary infection of dairy cows. J. Anim. Sci. 87:10-25.

Barrington G.M. \& Parish S.M. 2001. Bovine neonatal immunology. Vet. Clin. N. Am., Food Anim. Pract. 17(3):463-476.

Benesi F.J. 1993. Síndrome da asfixia neonatal dos bezerros: importância e avaliação clínica. Arq. Esc. Med. Vet. UFBA 16(1):38-48.

Chase C.C.L., Hurley D.J. \& Reber A.J. 2008. Neonatal immune development in the calf and its impact on vaccine response. Vet. Clin. N. Am., Food Anim. Pract. 24:87-104.

Cortese V.S. 2009. Neonatal Immunology. Vet. Clin. N. Am., Food Anim. Pract. 25:221-227.

Ewaschuk J.B., Unger S., O'Connor D.L., Stone D., Harvey S., Clandinin M.T. \& Field C.J. 2011. Effect of pasteurization selected immunecomponents of donated human breast milk. J. Perinatol. 31:593-598.

Feitosa F.L.F., Birgel E.H., Mirandola R.M.S. \& Perri S.H.V. 2001. Proteinograma sérico de bezerros holandeses do nascimento até um ano de vida. Revta Bras. Ciênc. Vet. 8(2):105-108.

Feitosa F.L.F., Camargo D.G., Yanaka R., Mendes L.C.N., Peiró J.R., Bovino F., Lisboa J.A.N., Perri S.H.V. \& Gasparelli E.R.F. 2010. Índices de falha de transferência de imunidade passiva (FTIP) em bezerros holandeses e nelores, às 24 e 48 horas de vida: valores de proteína total, de gamaglobulina, de imunoglobulina G e da atividade sérica de gamaglutamiltransferase, para o diagnóstico de FTIP. Pesq. Vet. Bras. 30(8):696-704.

Gomes V. 2008. Componentes imunológicos do colostro bovino: células, teores de imunoglobulinas e atividade bactericida dos fagócitos para a Escherichia coli enterotoxigênica (ECET). Tese de Doutorado em Medicina Veterinária, Faculdade de Medicina Veterinária e Zootecnia, Universidade de São Paulo, São Paulo, SP. 106p.

Goto M., Maruyama M., Kitadate K., Kirisawa R., Obata Y., Koiwa M. \& Iwai H. 1997. Detection of Interleukin-1b in sera and colostrum of dairy cattle and in sera of neonates. J. Vet. Med. Sci. 59(6):437-441.
Hagiwara K., Yamanaka H., Higuchi H.. Nagahata H., Kirisawa R. \& IwaI H. 2001. Oral administration of IL-1b enhanced the proliferation of lymphocytes and the 02 production of neutrophil in newborn calf. Vet. Immunol. Immunopathol. 81:59-69.

Hill J.A.G. 2010. Transferência de imunidade passiva colostral em bezerras neonatas da Região Metropolitana de Curitiba, Palmeira e Carambeí, Estado do Paraná e suas interrelações. Tese de Doutorado em Medicina Veterinária, Faculdade de Medicina Veterinária e Zootecnia, Universidade de São Paulo, São Paulo, SP. 149p.

Liebler-Tenorio E.M., Riedel-Caspari G. \& Pohlenz J.F. 2002. Uptake of colostral leucocytes in the intestinal tract of newborns calves. Vet. Immunol. Histhopatol. 85:33-40.

Madureira K.M. 2011. Citocinas IL-1 $\beta$, IL-6, TNF- $\alpha$ e IFN-g no sangue e colostro de fêmeas bovinas da raça Holandesa. Importância na transferência de imunidade passiva. Tese de Doutorado em Medicina Veterinária, Faculdade de Medicina Veterinária e Zootecnia, Universidade de São Paulo, São Paulo, SP. 85p.

Moraes M.P., Weiblen R., Silva A.M. \& Tobias F.L. 1997. Evolução da imunidade passiva em fêmeas bovinas da raça holandesa. Ciência Rural 27(3):435-440.

Morein B., Abusugra I. \& Blomqvist G. 2002. Immunity in neonates. Vet. Immunol. Histopathol. 87:207-213.

Ramírez-Santana C., Pérez-Cano F.J., Audí C., Castell M., Moretones M.G., López-Sabater M.C., Castellote C. \& Franch A. 2012. Effects of cooling and freezing storage on the stability of bioactive factors in human colostrum. J. Dairy Sci. 95:2319-2325.

Reber A.J., Lockwood A., Hippen A.R. \& Hurley D.J. 2006 .Colostrum induced phenotypic and trafficking changes in maternal mononuclear cells in a peripheral blood leukocyte model for study of leukocyte transfer to the neonatal calf. Vet. Immunol. Immunopathol. 109:139150.

Reber A.J., Donovan D.C., Gabbard J., Galland K., Aceves-Avila M., Holbert K.A., Marshall L. \& Hurley D.J. 2008a. Transfer of maternal colostral leukocytes promotes development of the neonatal immune system I. Effects on monocyte lineage cells. Vet. Immunol. Immunopathol. 123:186-196.

Reber A.J., Donovan D.C., Gabbard J., Galland K., Aceves-Avila M., Holbert K.A., Marshall L. \& Hurley D.J. 2008b. Transfer of maternal colostral leukocytes promotes development of the neonatal immune system. II. Effects on neonatal lymphocytes. Vet. Immunol. Immunopathol. 123:305313.

Riedel-Caspari G. 1993. The influence of colostral leukocytes on the course of an experimental Escherichia coli infection and serum antibodies in neonatal calves. Vet. Immunol. Immunopathol. 35:275-288.

Scheerlinck J.P.Y. 1999. Functional and structural comparison of cytokines in different species. Vet. Immunol. Immunopathol. 72:39-44.

Soares Filho P.M., Belém P.A.D., Ribeiro-Júnior J.I. \& Salcedo J.H.P. 2001. Concentrações de imunoglobulinas $\mathrm{G}$ em colostro de vacas mestiças Holandês-Zebu. Ciência Rural 31(6):1033-1037.

Sordillo L.M., Redmond M.J., Campos M., Warren L. \& Babiuk L.A. 1991. Cytokine activity in bovine mammary gland secretions during the periparturient period. Can. J. Vet. Res. 55:298-301.

Tizard I.R. 2008. Imunologia veterinária: uma introdução. $8^{\mathbf{a}}$ ed. Roca, São Paulo. 532p.

Yamanaka H., Hagiwara K., Kirisawa R. \& Iwai H. 2003a. Proinflammatory cytokines in bovine colostrum potentiate the mitogenic response of peripheral blood mononuclear cells from newborn calves through IL-2 and CD25 expression. Microbiol. Immunol. 47(6):461-468.

Yamanaka H., Hagiwara K., Kirisawa R. \& Iwai H. 2003b. Transient detection of proinflamatory cytokines in sera of colostrums-fed newborn calves. J. Vet. Med. Sci. 65(7):813-816.

Zaitseva M.B., Golding H., Betts M., Yamauchi A., Bloom E.T., Butler L.E., Stevan L. \& Golding B. 1995. Human peripheral blood CD4+ and CD8+T cells express Th1-like cytokine mRNA and proteins following in vitro stimulation with Heat-Inactivated Brucella abortus. Infect. Immunity 63(7):2720-2728. 